УДК 621.313.04: 629.423.24

ИССЛЕДОВАНИЕ ВОЗМОЖНОЙ ПРИЧИНЫ ПОВРЕЖДЕНИЯ ЭЛЕКТРИЧЕСКИМ ТОКОМ ПОДШИПНИКОВ АСИНХРОННЫХ ТЯГОВЫХ ЭЛЕКТРИЧЕСКИХ ДВИГАТЕЛЕЙ ЭЛЕКТРОПОЕЗДОВ «ЛАСТОЧКА»

\title{
A STUDY OF POSSIBLE REASONS OF THE DAMAGE BY ELECTRIC CURRENT OF TRACTION INDUCTION MOTORS BEARINGS ONBOARD OF ELECTRIC TRAINS "LASTOCHKA»"
}

\author{
Пустоветов М.Ю., Индылова Н.В. \\ Pustovetov M.Yu., Indylova N.V.
}

Донской государственный технический университет ( Ростов-на-Дону, Россия)

Don State Technical University (Rostov-on-Don, Russian Federation)

\begin{abstract}
Аннотация. Существует проблема повреждений подшипников асинхронных тяговых двигателей электропоездов «Ласточка» электрическим током. Основываясь на том, что подшипники имеют керамическое изоляционное покрытие, а случаев его электрического пробоя не зафиксировано, авторами выдвинута версия о том, что через подшипник как через электрическую емкость протекает высокочастотный ток. Анализ показал, что причиной тока может быть радиосвязь стандарта GSM-R. Предложены технические решения по борьбе с повреждениями подшипников: использование валозаземляющих колец и замена подшипников на другие с керамическими телами качения.

Ключевые слова: подшипник, преобразователь частоты, асинхронный тяговый двигатель, электропоезд, высокочастотный ток, кольцо валозаземляющее.
\end{abstract}

Дата принятия к публикации:

26.11.2018 Дата публикации:

25.12.2018

\section{Сведения об авторах:}

Пустоветов Михаил Юрьевич - кандидат технических наук, доцент, доцент каф. «Интеллектуальные электрические сети» Донского государственного технического университета, mgsn2006@yandex.ru.

Индылова Надежда Вячеславовна - студент факультета «Энергетика и нефтегазопромышленность» Донского государственного технического университета, indylova2015@mail.ru.

\section{Введение.}

По информации ОАО «РЖД» имеются многочисленные случаи повреждений электрическим током подшипников качения асинхронных тяговых электродвигателей,
Abstract. There is a problem of damage of bearings of traction induction motors of electric trains "Lastochka" by electric current. Based on the fact that the bearings have a ceramic insulation coating, and the cases of its electrical breakdown is not fixed, the authors put forward a version that a high-frequency current flows through the bearing as through an electric capacitance. The analysis show that the cause of the current can be a radio standard GSM-R The proposed technical solution against the damage of bearings: the use of grounding shaft rings and replace the bearings on the other with ceramic rolling elements.

Keywords: bearing, frequency converter, traction induction motor, electric train, high-frequency current, shaft-grounding ring.

Date of acceptance for publication:

26.11.2018 Date of publication:

Authors' information:

Mikhail Yu. Pustovetov - Candidate of Technical Sciences, Associate Professor of the Department "Intelligent electrical networks" at Don State Technical University,mgsn2006@yandex.ru.

Nadezhda V. Indylova - Student of Faculty "Energy and oil and gas industry" at Don State Technical University, indylova2015@mail.ru.

питаемых от преобразователей частоты, электропоездов «Ласточка»:

- типа ЭС2Г, эксплуатируемых на Московском центральном кольце;

- типа ЭС1 на полигоне Адлер - Туапсе. 
Последствия повреждений подшипников электрическим током проявляются в виде повышенного шума и вибрации при работе асинхронных тяговых электродвигателей. К августу 2017 года подобные неисправности зарегистрированы на 21 поезде ЭС2Г, а также на 6 поездах ЭС1. Характерным является повреждение подшипников с приводной стороны всех четырех асинхронных тяговых электродвигателей на первом головном вагоне №1 (составность электропоезда «Ласточка» - 5 вагонов, головными являются ва- гоны №1 и №5, они идентичны по конструкции, но подшипники асинхронных тяговых электродвигателей на вагоне №5 током не повреждаются). Несмотря на ряд проведенных исследований и принятых мер, повреждения подшипников продолжаются. Они проявляются при пробеге электропоезда в среднем 200000 км. Вид подшипника асинхронного тягового электродвигателя электропоезда «Ласточка» и его повреждений от протекания электрического тока показаны на рис. 1 (фото фирмы Siemens).

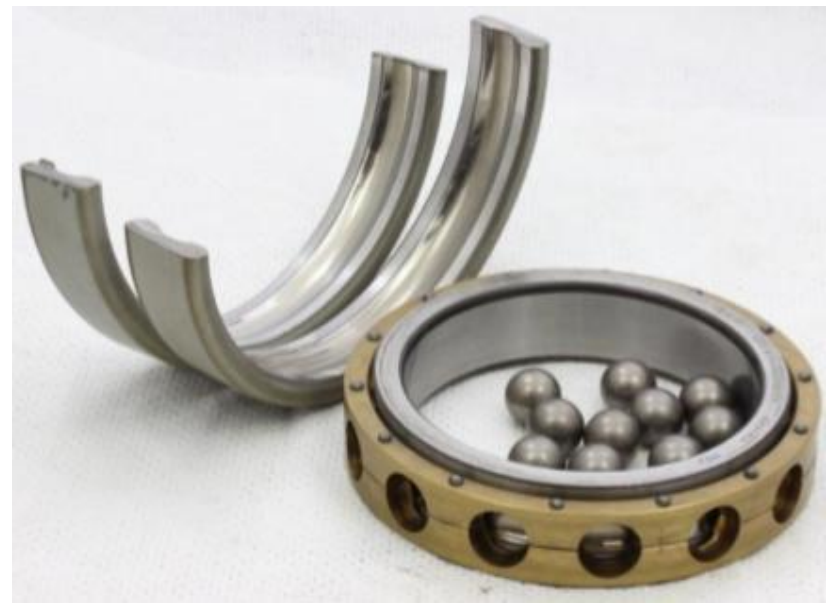

a)

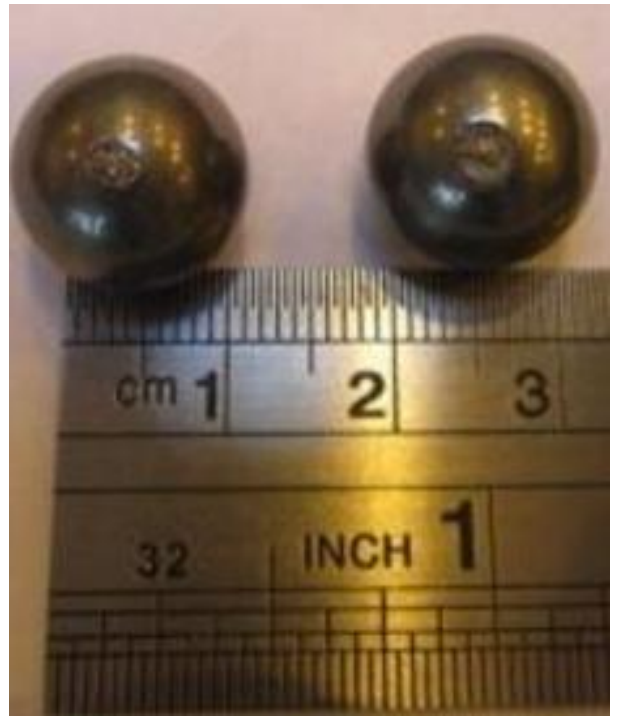

б)

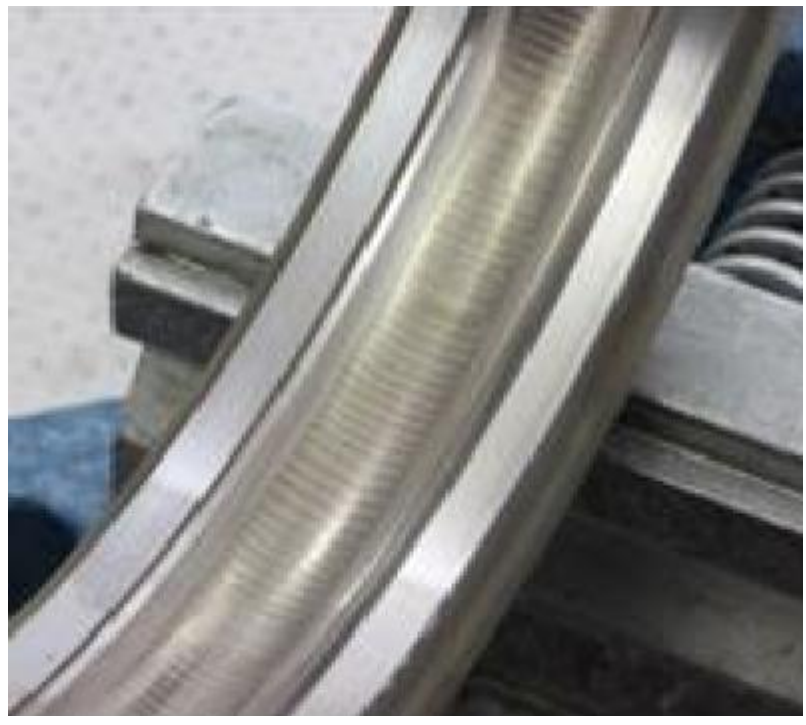

в)

Рис. 1. Вид подшипника асинхронного тягового электродвигателя электропоезда «Ласточка» и его повреждений от протекания электрического тока: а - распиленный шариковый подшипник электродвигателя; б - повреждение от протекания тока в виде кратера на теле качения подшипника; в - повреждение внутреннего кольца подшипника в виде рифления поверхности 
Учитывая специфику работы асинхронного тягового электродвигателя, питаемого от ПЧ, оба подшипника имеют керамическую электрическую изоляцию с пробивным напряжением 1000 В постоянного тока, покрывающую наружную поверхность внешнего кольца. Подобные подшипники описаны в $[1,2]$, где сказано, что по виду следов протекания тока на подшипниках невозможно определить, постоянный был ток или переменный. Также в $[1,2]$ сообщается, что повреждения подшипников происходят при плотности тока $J \geq 1 \mathrm{~A} / \mathrm{Mm}^{2}$.

Первоначально возникла версия, что электрическая изоляция подшипников может пробиваться значительным напряжением вала, возникновение которого характерно для асинхронных электрических машин, обмотка которых питается от ПЧ. Исходя из изложенного в [3], а также учитывая, что напряжение на входе автономного инвертора напряжения тягового привода электропоезда «Ласточка» составляет $3000 \mathrm{~B}$, теоретически можно предположить достижение напряжением вала асинхронного тягового электродвигателя значений, превышающих пробивное напряжение изоляции подшипников. Но такая версия не отвечает на вопрос, почему повреждаются подшипники на вагоне №1, но не повреждаются на вагоне №5, где асинхронные тяговые электродвигатели питаются по идентичной схеме.

Существенным дополнительным обстоятельством является то, что случаи электрического пробоя изоляции подшипников не были обнаружены: дефектный подшипник демонтировался, сопротивление изоляции проверялось в сухом и увлажненном состоянии. Известно, что диэлектрические свойства твердых диэлектриков, подвергшихся электрическому пробою, не восстанавливаются.

\section{Постановка задачи.}

Защитное заземление поезда соединено только на вагоне № 4 (на этом вагоне оси трех колесных пар оборудованы заземляющими угольными щетками), чтобы избежать протекания тяговых токов через кабели и экранирование переходных соединений вагонов. Сопротивление штатного заземления (кузов электропоезда - рельс) не должно пре- вышать 0,05 Ом. Полагая, что сопротивление штатного заземления прямо пропорционально длине проводников, можно в первом приближении предположить, что 0,05 Ом - это сопротивление наиболее длинного пути заземления (от вагона №1 до вагона №4, т.е. четыре вагона). Длина пути заземления от вагона №5 до вагона №4 (два вагона) в два раза короче, поэтому его сопротивление примем равным 0,025 Ом.

Исходя из того, что следы протекания тока через изолированный подшипник присутствуют, а пробой изоляции отсутствует, существуют условия, при которых протекание тока через изолированный подшипник происходит без пробоя изоляции. В $[1,2]$ изготовитель изолированных подшипников сообщает о том, что как элемент электрической цепи такой подшипник может быть представлен параллельным соединением активного сопротивления $R>1 \mathrm{MOм} \mathrm{и} \mathrm{емкости} C$ $=2 \ldots 20 \mathrm{H} \Phi$ в зависимости от размера подшипника. Поскольку внутренний диаметр моторного подшипника тягового двигателя «Ласточки» можно определить по рис. 1 как $d=95$ мм, то, используя [2], для данного типоразмера подшипников можно оценить $C=$ 6,7 нФ.

Используя представленное на рис. 1, б изображение следов протекания тока на шариках подшипников, можно оценить площадь канала протекания тока. Диаметр токовых повреждений составляет $3 \ldots 4$ мм, а их

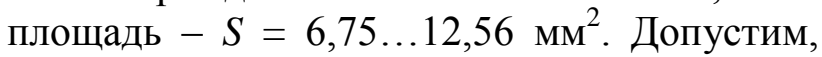
что ток единовременно протекает через подшипник лишь в одной точке контакта. Величину тока, соответствующую пороговой плотности тока $J \geq 1 \mathrm{~A} / \mathrm{Mм}^{2}$, можно определить как $I=S J=6,75 \ldots 12,56$ А. Зная величину сопротивления, через которое такой ток протекает, по закону Ома можно определить величину напряжения, вызвавшего его протекание. Так как сопротивление $R$ изолированного подшипника велико, вычислим величину емкостного реактивного сопротивления:

$$
x_{C}=\frac{1}{2 \cdot \pi \cdot f \cdot C}
$$

где $f$ - частота протекающего через подшипник тока, Гц. 
Сводные результаты расчетов для различных частот тока, появление которых ожидаемо на электропоезде

\begin{tabular}{|c|c|c|c|c|}
\hline $\begin{array}{c}\text { Источник сигнала } \\
\text { (помехи) }\end{array}$ & $\begin{array}{c}\text { Частота } \\
\text { тока } f, \\
\text { МГц }\end{array}$ & $\begin{array}{l}\text { Емкостное } \\
\text { реактивное } \\
\text { сопротивле- } \\
\text { ние } x_{C}, \text { Ом }\end{array}$ & $\begin{array}{c}\text { Напряжение } U, \mathrm{~B}, \text { необхо- } \\
\text { димое для обеспечения про- } \\
\text { текания через подшипник } \\
\text { тока силой } 1 \mathrm{~A} / \mathrm{mм}^{2}\end{array}$ & Примечание \\
\hline $\begin{array}{l}\text { Переключение } \\
\text { высоковольтных } \\
I G B T \text { тягового } \\
\text { преобразователя }\end{array}$ & $\begin{array}{l}0,001 \\
0,003\end{array}$ & 23766,5 & $\begin{array}{c}160424,0 \ldots 298507,4 \\
53774,7 \ldots 99502,5\end{array}$ & $\begin{array}{c}x_{C}>>0,05 \\
\text { Ом }\end{array}$ \\
\hline $\begin{array}{l}\text { Переключение } \\
I G B T\end{array}$ & $\begin{array}{c}0,01 \\
0,1\end{array}$ & $\begin{array}{c}2376,7 \\
237,7\end{array}$ & $\begin{array}{c}16042,4 \ldots 29850,7 \\
1604,2 \ldots 2985,1\end{array}$ & $\begin{array}{c}x_{C}>>0,05 \\
\text { OM }\end{array}$ \\
\hline $\begin{array}{l}\text { Фронты импульсов } \\
\text { напряжения при } \\
\text { переключениях } \\
\text { высоковольтных } \\
I G B T \\
\end{array}$ & 1 & 23,8 & $160,4 \ldots 298,5$ & $\begin{array}{c}x_{C}>>0,05 \\
\text { Ом }\end{array}$ \\
\hline $\begin{array}{l}\text { Поездная радио- } \\
\text { связь КВ }\end{array}$ & 2,13 & 11,158 & $75,3 \ldots 140,1$ & $\begin{array}{c}x_{C}>>0,05 \\
\text { Oм }\end{array}$ \\
\hline $\begin{array}{l}\text { Фронты импульсов } \\
\text { напряжения при } \\
\text { переключениях } \\
I G B T\end{array}$ & 10 & 2,736 & $16,038 \ldots 29,843$ & $\begin{array}{c}x_{C}>>0,05 \\
\text { Oм }\end{array}$ \\
\hline $\begin{array}{l}\text { Поездная радио- } \\
\text { связь УКВ }\end{array}$ & 151 & 0,158 & $1,067 \ldots 1,984$ & $\begin{array}{c}x_{C}>0,05 \\
\text { Ом }\end{array}$ \\
\hline $\begin{array}{l}\text { Поездная радио- } \\
\text { связь GSM-R }\end{array}$ & 876 & 0,0269 & $0,182 \ldots 0,338$ & $\begin{array}{c}x_{C}<0,05 \\
\text { Ом, но } \\
x_{C}>0,025 \\
\text { Ом }\end{array}$ \\
\hline
\end{tabular}

Тогда величина действующего значения напряжения, являющегося причиной протекания тока составит

$$
U=I \cdot x_{C}
$$

Результаты.

Результаты расчетов для различных частот, появление которых ожидаемо на электропоезде, сведены в табл. 1.

Из данных табл. 1 следует, что в вагоне №1 ток пойдет через подшипник на рельс через стальные вал асинхронного тягового электродвигателя, муфту, тяговый редуктор, ось колесной пары и колесо, а не через штатное заземление на частоте радиосвязи $G S M$ $R$. В вагоне №5 ток пойдет указанным путем только частично, так как его величина будет недостаточна для обеспечения пороговой плотности тока $1 \mathrm{~A} / \mathrm{Mm}^{2}$.

Поездные радиостанции $G S M-R$ на электропоезде «Ласточка» расположены в кабинах вагонов №1 и №5. На крышах этих же вагонов расположены антенны GSM-R [4] с подводимой мощностью не более 100 Вт. Основание антенны имеет надежный гальванический контакт с кузовом вагона, изготовленным из алюминиевого сплава. В [4] указано, что электрическая безопасность антенны обеспечивается гальваническим соединением центрального вывода антенного разъема с корпусом транспортного средства посредством прямого контакта центральной жилы питающего кабеля с вибратором и да- 
лее через несущую стойку с основанием антенны.

С другой стороны, антенна $G S M-R$ может воспринимать электромагнитные помехи, возникающие, например, при скольжении пантографа по проводу контактной сети. Так, в [5] приведен пример осциллограммы напряжения высокочастотной помехи, наведенной на антенне $G S M-R$, установленной на крыше вагона на расстоянии примерно 80 м от пантографа локомотива. Амплитуда сигнала составила до 0,8 В.

Нужно отметить, что по доступным данным поездная радиосвязь $G S M-R$ в России используется на полигоне Адлер - Туапсе (с 2014 г.), на Московском центральном кольце (с 2016 г.) и на полигоне Санкт-Петербург Бусловская (с 2016 г.). На последнем полигоне электропоезда «Ласточка» эксплуатируются на маршруте Санкт-Петербург - Выборг, но на этом направлении токовые повреждения подшипников асинхронных тяговых электродвигателей не зафиксированы.

С точки зрения решения проблемы, то есть нахождения относительно дешевого и удобного для практической реализации способа исключения повреждения изолированных подшипников асинхронных тяговых электродвигателей электрическим током, можно предложить использование с приводной стороны электродвигателя вагона №1 электропоездов валозаземляющих колец (shaft grounding ring) [6 - 8], оснащенных волокнами токопроводящей микрофибры, обеспечивающих контактный и бесконтактный токосъем с вращающегося вала. Эти кольца рекомендуются производителями для применения, в том числе, на электродвигателях, питаемых от преобразователей частоты, чтобы обеспечить путь с малым сопротивлением для протекания токов утечки, обусловленных напряжением вала, на землю, минуя подшипники.

\section{Заключение.}

В рассматриваемом случае назначением валозаземляющего кольца будет, напротив, обеспечение пути протекания тока с корпуса асинхронного тягового электродвигателя, гальванически связанного с кузовом вагона, на его вал и далее на землю, то есть мимо подшипников. К сожалению, не удалось найти данные о сопротивлении валозаземляющего кольца на частотах порядка 1 ГГц, чтобы быть уверенными в эффективности устройства для решения описываемой проблемы. Расчетные и экспериментальные данные [7] о сопротивлении валозаземляющих колец не дают однозначного ответа, что оно меньше 0,05 Ом. Возможно, правильным для рассматриваемого случая будет использование колец с волокнами токопроводящей микрофибры, имеющими медное покрытие [7].

Несмотря на то, что валозаземляющие кольца способны уберечь подшипники асинхронных тяговых электродвигателей электропоезда от протекания тока, это не решает дает окончательного решения проблемы, так как существует путь утечки высокочастотного тока на землю через тяговый редуктор, а не через штатное заземление. В этой связи целесообразно рассмотреть вопрос об использовании изолированных подшипников другого типа - с керамическими телами качения $[1,2]$. По данным изготовителя их типичные значения электрической емкости примерно в 100 раз ниже, чем для подшипников с керамическим изоляционным покрытием. Это не позволит току утечки через подшипник достигать опасной плотности в 1 $\mathrm{A} / \mathrm{MM}^{2}$.

Также, возможно, следует нормировать мощность сигнала $G S M-R$ для электроподвижного состава. В [9], несмотря на упоминание цифровых систем радиосвязи (к ним относится $G S M-R$ ) на борту электропоездов, какие-либо характеристики и ограничения их сигналов отсутствуют. 


\section{Список литературы}

1. Токоизолирующие подшипники качения FAG. Защита от повреждений, вызванных прохождением электрического тока. Техническая информация. Schaeffler gruppe industrie. URL: http://www.podshipnik.ru/ docs/fag_current_opt.pdf (дата обращения 13.11.2018).

2. Current-Insulating Bearings Rolling bearings for prevention of damage due to current passage. Schaeffler group industrial. URL: http://www.reliancebearing.ie/wpcontent/uploads/2010/08/FAG-InsulatedBearings.pdf (дата обращения 13.11.2018).

3. Пустоветов, М.Ю. Теоретическое исследование потенциала нейтральной точки нагрузки и токов утечки в тяговом асинхронном электроприводе электровоза постоянного тока / М.Ю. Пустоветов // Известия Транссиба. - 2012. - №4 (12). - С. 116 122.

$4 . \quad$ Лаборатория АЛ1/460/900. Антенна ПАСПОРТ. 657700 5-008-62837180-10 ПС. URL: http:// http://www.rclab.ru/sites/default/ files/pasport_inf_al1_460_900_01-10-12.pdf (дата обращения 13.11.2018).

5. Dudoyer S., Ben Slimen N., Deniau V., Berbineau M. Reliability of the GSM-R Communication System against Railway Electromagnetic Interferences. $9^{\text {th }}$ World Congress on railway research, 22-26 May 2011, Lille. URL: http://www.railway-research.org/IMG/ pdf/h03_dudoyer_stephen.pdf (дата обращения 13.11.2018) .

6. Oh H.W., Willwerth A. Shaft Grounding - A Solution to Motor Bearing Currents // ASHRAE Transactions. - Vol. 114, Part 2. URL: https://www.est-aegis.com/datasheets/ ASHRAE_SL-08-025_Shaft_Grounding_A_ Solution_to_Motor_Bearing_Currents.pdf (дата обращения 13.11.2018).

7. Muetze A., Oh H.W. Current-Carrying Characteristics of Conductive Microfiber Electrical Contact for High Frequencies and Current Amplitudes: Theory and Applications /A. Muetze, H. W. Oh // IEEE Transactions on power electronics. - Vol. 25. - No. 8. - P. 20822092.

8. Muetze A., Oh H.W. Design Aspects of

\section{References}

1. Current-insulating rolling bearings FAG. Protection against damage caused by the passage of electric current. Technical information. Schaeffler gruppe industrie. URL: http://www.podshipnik.ru/docs/fag_current _opt.pdf (date of appeal 13.11.2018) (In Russian)

2. Current-Insulating Bearings Rolling bearings for prevention of damage due to current passage. Schaeffler group industrial. URL: $\quad$ http://www.reliancebearing.ie/wpcontent/uploads /2010/08/FAG-InsulatedBearings.pdf (date of appeal 13.11.2018).

3. Pustovetov M.Yu. Theoretical study of the potential of the neutral point of the load and the leakage current in the traction asynchronous electric drive of the DC electric locomotive. Izvestiya Transsiba, 2012, No. 4 (12), pp. 116-122. (In Russian)

4. Radio communication laboratory. AL1/460/900. Locomotive antenna. PASSPORT. 65 7700 5-008-62837180-10 PS. URL: http:// www.rclab.ru/sites/default/files/pasport _inf_al1_460_900_01-10-12.pdf (date of appeal 13.11.2018). (In Russian)

5. Dudoyer S., Ben Slimen N., Deniau V., Berbineau M. Reliability of the GSM-R Communication System against Railway Electromagnetic Interferences. $9^{\text {th }}$ World congress on railway research, 22-26 May 2011, Lille. URL: http://www.railway-research.org/IMG/ pdf/h03_dudoyer_stephen.pdf (date of appeal 13.11.2018).

6. Oh H.W., Willwerth A. Shaft Grounding - A Solution to Motor Bearing Currents. ASHRAE Transactions, Vol. 114, Part 2. URL: https://www.est-aegis.com/datasheets /ASHRAE_SL-08-025_Shaft_Grounding_A_ Solution_to_Motor_Bearing_Currents.pdf (date of appeal 13.11.2018).

7. Muetze A., Oh H.W. Current-Carrying Characteristics of Conductive Microfiber Electrical Contact for High Frequencies and Current Amplitudes: Theory and Applications. IEEE Transactions on power electronics, Vol. 25, No. 8, pp. 2082-2092.

8. Muetze A., Oh H.W. Design Aspects of Conductive Microfiber Rings for Shaft Grounding Purposes. Proc. 42nd IAS Ann. Conf., 
Conductive Microfiber Rings for Shaft Grounding Purposes // Proc. 42nd IAS Ann. Conf., New Orleans, IEEE Transactions on Industry Applications, October 2007, pp. 229-236.

9. ГОСТР 55434-2013. Электропоезда. Общие технические требования. - М.: Стандартинформ, 2014. - 42 с.
New Orleans, IEEE Transactions on Industry Applications, October 2007, pp. 229-236.

9. GOST R 55434-2013. Elektricheskie poezda. Obshchie tekhnicheskie trebovaniya [Electric train. General technical requirements]. Moscow, STANDARTINFORM, 2014. 42 p. (In Russian) 